\title{
Urbanized Area Landslide Susceptibility Assessment Using Time-series Analysis: A Case Study in Gyeongsangnam-do, Republic of Korea
}

\author{
Ho Gul Kim* \\ Department of Human Environment Design, Cheongju University, \\ Daeseong-ro 298, Cheonwon-gu, Cheongju 28503, ROK
}

(Received March 30, 2021; accepted June 23, 2021; online published June 30, 2021)

Keywords: landslide damage, traffic area, priority for adaptation measures, spatial distribution model, forest adjacent areas

Landslide damage has occurred in many countries, and research on landslide susceptibility assessment is being actively conducted in response. In Gyeongsangnam-do (Gyeongnam), Republic of Korea (ROK), landslides are frequent, making it imperative that high-susceptibility areas are identified to reduce damage and loss of life. The purpose of this study was therefore to establish a predictive model for landslide-susceptible areas and identify urbanized locations exposed to a high risk of landslides on an ongoing basis. This study led to landslide locations for the previous nine years being precisely identified and a composite occurrence map being created. Landslide location changes over time were confirmed, and repetition patterns were identified. Relationships between landslide locations and urbanized areas were analyzed, which allowed high-susceptibility traffic areas, residential areas, and public facilities to be identified, and their characteristics analyzed. The results of this study can be applied to reduce property damage and prevent loss of life from landslides in the ROK. Its methodology can also be used as a landslide susceptibility analysis framework and as a guide for establishing countermeasures in urbanized areas worldwide with significant landslide susceptibility. This study emphasizes the need for periodic landslide sensing and monitoring, and illustrates the importance of collecting information on locations where landslides occur as material for landslide research.

\section{Introduction}

Numerous, frequent, and widespread landslides are caused by the heavy rainfall and typhoons that characterize summer in the Republic of Korea (ROK) ${ }^{(1)}$ and often lead to loss of life and property damage. Over the 10 years from 2008 to 2017, landslides damaged an area of 2304 ha, led to a loss of 55 lives, and required KRW 450.4 billion in restoration costs. ${ }^{(2)}$ Landslide damage is large-scale to the extent that an annual damage prevention budget of more than KRW 100 billion is invested in the ROK for dam building, anchoring structures, and stabilizing steeply sloping areas. ${ }^{(3)}$

*Corresponding author: e-mail: khgghk87@gmail.com https://doi.org/10.18494/SAM.2021.3375 
In Gyeongsangnam-do (Gyeongnam) province, landslide damage occurred in nine of the 11 years from 2008 to 2019, and while different areas were affected, large and small landslides have been common. A study analyzing landslide-susceptible areas is needed to prevent property damage, injuries, and loss of life from landslides in Gyeongnam. By analyzing landslide locations, areas with similar characteristics can be identified, potentially making it possible to protect areas with a high probability of landslide occurrence. ${ }^{(4)}$ In addition, it is necessary to conduct a more reliable landslide susceptibility study based on information on landslides that occurred in various years.

Several previous studies have analyzed landslide-susceptible areas using spatial distribution models. Examples include a study using MaxEnt species distribution modeling (MaxEnt) to create a landslide susceptibility map for Garhwal district in northern India, ${ }^{(5)}$ a study analyzing landslide-susceptible areas using clay mineral index values extracted from ASTER satellite imagery, ${ }^{(6)}$ a study evaluating the predictive power of landslide sensitivity using MaxEnt and frequency ratio methods in Cinque Terre, Italy, ${ }^{(7)}$ and a study leading to the creation of a landslide susceptibility map through an ensemble of various spatial distribution models (such as MaxEnt, artificial neural network, and support vector machine). ${ }^{(8)}$ These were all carried out to prevent damage by analyzing landslide-susceptible areas.

There have been no such long-term time-series studies on landslide locations in the ROK, which are needed for Gyeongnam and other landslide-prone areas across the country. It is important to use time-series data to establish the characteristics of landslide-susceptible areas, as such an approach can assist in prioritizing the development of long-term countermeasures. ${ }^{(9)}$ This is particularly important for areas with a long history of landslides, such as Gyeongnam. On the other hand, property damage and human impacts from landslides mainly occur in areas adjacent to forested and urbanized areas. The July 2011 Mt. Umyeon landslide occurred in Seocho-gu, Seoul, ${ }^{(10)}$ and caused 18 deaths. Since Mt. Umyeon is located in the middle of an urbanized area, the loss of life and property damage from the event were severe. Therefore, analyzing landslide susceptibility in urbanized areas can clearly make an important contribution to reducing property damage and preventing loss of life. ${ }^{(11)}$

The purpose of this study was therefore to establish a predictive model for landslidesusceptible areas and identify urbanized locations exposed to high risks of landslides on an ongoing basis. The initial purposes of the study were to identify environmental variables that have contributed to landslides in Gyeongnam and to optimize a prediction model for landslidesusceptible areas. A highly reliable model was then constructed by combining variables such as rainfall, wind speed, topography, forest vegetation, and land use. Susceptible areas identified by the model helped reveal locations with characteristics similar to those where landslides had previously occurred and can be used as important data in prioritizing the establishment of preventative measures.

This study then focused on finding urbanized areas in Gyeongnam that are constantly exposed to high levels of landslide susceptibility. The thinking behind this was that if specific areas with high landslide susceptibility can be identified using time-series analysis on an ongoing basis, this will assist regional governments in prioritizing budget allocations for landslide responses. This will be a particularly useful contribution to reducing property damage 
and preventing loss of life in Gyeongnam cities, where landslides continue to occur. This study emphasizes the need for periodic landslide sensing and monitoring, and illustrates the importance of collecting information on locations where landslides occur as material for landslide research.

\section{Materials and Methods}

\subsection{Scope}

Gyeongnam province, ROK, was used as the study area. This province is located in southeast ROK, and is bordered by the South Sea to the south, Busan-si and Ulsan-si to the east, Jeollanamdo and Jeollabuk-do provinces to the west, and Daegu-si and Gyeongsangbuk-do province to the north. It has an area of $\sim 10539 \mathrm{~km}^{2}$ and a population of $\sim 3336000$ as of 2021. In Gyeongnam, the average annual temperature is $14-15^{\circ} \mathrm{C}$ on the south coast and $11-14{ }^{\circ} \mathrm{C}$ elsewhere, with rainfall in the range of 1229-2007 mm. ${ }^{(12)}$ Data covering 2008-2019 were used for this study, as this range included the most extensive data on landslide occurrences.

\subsection{Landslide locations}

Data from 520 landslides that occurred in Gyeongnam during the 2008-2019 study period were used in this study (Table 1). The landslide location data were collected by Korea Forest Service. Landslide locations and times differed each year, although the major causes were always torrential rain, strong wind, typhoons, and earthquakes, with torrential rain and typhoons being the most common causes. Although the landslide locations differed year-by-year, the number located in central Gyeongnam was consistently low (Fig. 1).

\subsection{Environmental variables for landslide susceptibility analysis}

To analyze landslide-susceptible areas, data were acquired for environmental variables strongly associated with landslide occurrence-rainfall, wind speed, topography, vegetation,

Table 1

Information on landslide occurrences in Gyeongnam for 2008-2019.

\begin{tabular}{lccc}
\hline Year & $\begin{array}{c}\text { Number of landslide } \\
\text { locations }\end{array}$ & $\begin{array}{c}\text { Occurrence periods } \\
\text { (month / day) }\end{array}$ & Causes \\
\hline 2008 & 11 & $5 / 26-27$ & Heavy rainfall, earthquake \\
2009 & 72 & $7 / 13-23$ & Heavy rainfall \\
2010 & 15 & $3 / 30,7 / 18,8 / 17$ & Strong wind, heavy rainfall \\
2011 & 150 & $7 / 14,8 / 6-10$ & Heavy rainfall, Typhoon Muifa \\
2012 & 166 & $9 / 17$ & Typhoon Sanba \\
2014 & 23 & $8 / 25$ & Heavy rainfall \\
2016 & 18 & $8 / 26$ & Typhoon Chaba \\
2018 & 24 & $8 / 26-9 / 1$ & Typhoon Maysak \\
2019 & 41 & $7 / 19-21,10 / 2-3$ & Typhoon Danas, Typhoon Mitag \\
\hline Total & 520 & & \\
\hline
\end{tabular}




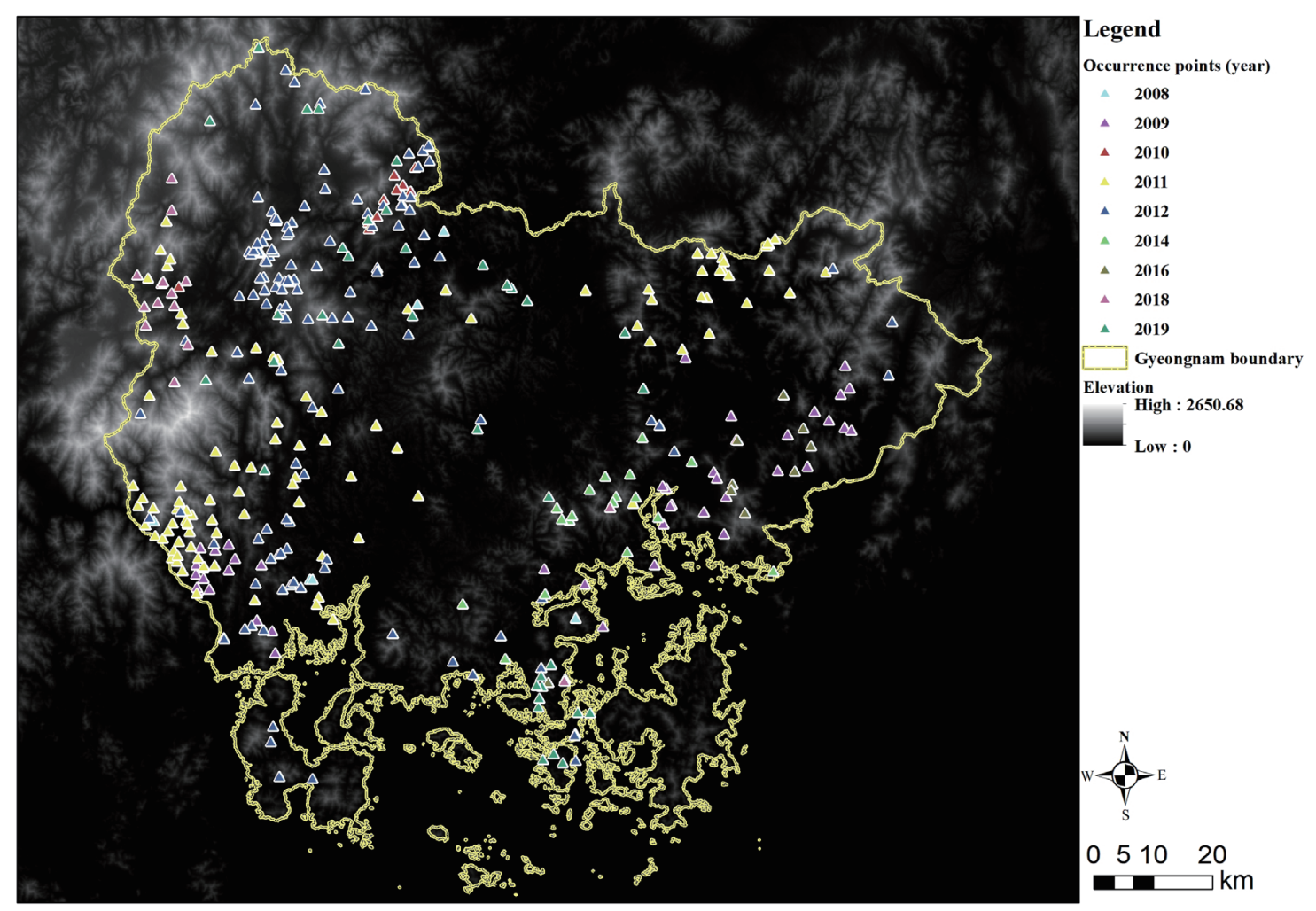

Fig. 1. (Color online) Landslide locations in Gyeongnam over the period 2008-2019.

and land use (Table 2). Heavy rainfall has been identified as the primary cause of shallow landslides; ${ }^{(13)}$ thus, various rainfall variables were analyzed to determine which were relevant. Wind speed can also be an important factor in landslide occurrence, ${ }^{(14)}$ while soil is the principal material displaced during landslides and debris flows. ${ }^{(15)}$ Other topographic variables are also important factors contributing to landslides, ${ }^{(16)}$ and it has been reported that vegetation can affect the landslide occurrence probability via its root cohesion, load, and rainfall interception behavior. $^{(17)}$

For rainfall and wind speed, information on the landslide year and date was established, and the associated weather observation data were obtained from Korea Meteorological Administration. ${ }^{(18)}$ Rainfall variables collated included maximum precipitation duration, maximum 10 min precipitation value, and maximum hourly and daily precipitation values, while wind data included maximum instantaneous wind speed and range. The remaining environmental variables were produced using available data because time series covering the entire study period were not available. Unlike rainfall and wind speed, the topography, vegetation, and land use variables did not change abruptly over time; data for variables related to topography (elevation, slope, and aspect) were obtained from the National Geographic Information Institute, while Korea Forest Service data were used for parent rock and topography classifications and for slope type, soil depth, soil texture, and soil drainage data. For variables related to vegetation [forest type, age class, and diameter at breast height (DBH)], additional 
Table 2

Environmental variables considered in constructing the landslide spatial distribution model.

\begin{tabular}{|c|c|c|c|}
\hline Class & Variable (unit) & Variable type & Source \\
\hline \multirow{4}{*}{ Rainfall } & $\begin{array}{l}\text { Maximum duration of } \\
\text { precipitation }(\mathrm{mm})\end{array}$ & Continuous & \multirow{6}{*}{$\begin{array}{l}\text { Korea Meteorological Administration } \\
\qquad(2009-2019)\end{array}$} \\
\hline & $\begin{array}{l}\text { Maximum value of precipitation } \\
\text { in } 10 \mathrm{~min}(\mathrm{~mm})\end{array}$ & Continuous & \\
\hline & $\begin{array}{c}\text { Maximum value of precipitation } \\
\text { in } 1 \mathrm{~h}(\mathrm{~mm})\end{array}$ & Continuous & \\
\hline & $\begin{array}{l}\text { Maximum value of daily } \\
\text { precipitation }(\mathrm{mm})\end{array}$ & Continuous & \\
\hline \multirow[t]{2}{*}{ Wind } & $\begin{array}{l}\text { Maximum instantaneous } \\
\text { wind speed }(\mathrm{m} / \mathrm{s})\end{array}$ & Continuous & \\
\hline & Maximum wind speed (m/s) & Continuous & \\
\hline \multirow{9}{*}{ Topography } & Elevation $(\mathrm{m})$ & Continuous & \multirow{3}{*}{$\begin{array}{l}\text { National Geographic Information Institute } \\
\qquad(2015)\end{array}$} \\
\hline & Slope $\left(^{\circ}\right)$ & Continuous & \\
\hline & Aspect $\left(^{\circ}\right)$ & Continuous & \\
\hline & $\begin{array}{l}\text { Mother rock intermediate } \\
\text { classification }\end{array}$ & Categorical & \multirow{6}{*}{$\begin{array}{l}\text { Korea Forest Service } \\
\text { (2018) }\end{array}$} \\
\hline & Terrain classification & Categorical & \\
\hline & Slant type & Categorical & \\
\hline & Soil depth & Continuous & \\
\hline & Soil texture & Categorical & \\
\hline & Soil drainage & Continuous & \\
\hline \multirow{3}{*}{ Vegetation } & Forest type & Categorical & \multirow{3}{*}{$\begin{array}{l}\text { Korea Forest Service } \\
\text { (2011) }\end{array}$} \\
\hline & Age class & Continuous & \\
\hline & $\mathrm{DBH}$ & Continuous & \\
\hline Land use & Land use type & Categorical & Ministry of Environment (2010) \\
\hline
\end{tabular}

information from Korea Forest Service were used. Regarding land use information, data were available for 2000, 2010, and 2019. Thus, the 2010 data, which fell within the study review period, were used.

\subsection{Landslide susceptibility analysis method}

MaxEnt was used as the spatial distribution model for landslide-susceptible area analysis. This is a machine learning model that can estimate the probability of occurrence of a landslide in a corresponding grid using only landslide location information and has shown relatively good reliability in comparison with other spatial distribution models. ${ }^{(19)}$ This reliability has led to it being applied in other recent studies, such as an assessment of its ability to predict landslide sensitivity, ${ }^{(7)}$ and landslide sensitivity analysis in comparison with other models. ${ }^{(5)}$

The model was optimized for use as a landslide susceptibility model. This optimization process started with correlation analysis between the environmental variables. Then, the model was populated with data for all 19 environmental variables. Variables with small contributions to the results in several target years were then identified, their data were removed, and the model was then run. In this step, the correlation between variables was considered. In the next step, the effects of the removed variables on the reliability of the model were considered, and if the 
reliability had not been adversely affected, then the variable was permanently excluded from further model runs.

As a machine learning model, MaxEnt produced slightly different results each time it was run, even when the same input data were used. To consider the uncertainty arising from the model operation, it was run five times for each time period. Susceptible areas were reviewed for the nine landslide years of the study period by applying information on annual landslide locations, rainfall, and wind speed. Then, when creating annual susceptibility maps, the average values from the five model runs were used. As a reliability benchmark, the area under the curve (AUC) metric, derived through receiver operating characteristic (ROC) curve analyses, was used.

Landslide susceptibility maps were derived by applying threshold values to landslide probability maps. To examine the cumulative landslide susceptibility of the area that had landslides over the nine-year study period, a comprehensive landslide map was created by overlaying the annual landslide susceptibility maps. To locate urbanized areas in Gyeongnam that were continuously susceptible to landslides, the comprehensive landslide map was then overlaid with the urbanized areas of the land cover classification map. By following this procedure, urban areas with high susceptibility to landslides were identified.

\section{Results}

\subsection{Reliability of annual landslide susceptibility analyses}

Through the optimization of the landslide-susceptible area model, three variables that contributed little to the model, were weakly related to the response curves, and had high correlations with other variables (maximum 10 min rainfall, slope type, and DBH) were excluded, leaving 16 environmental variables. The reliability of the model for each period was then derived, with the results listed in Table 3. In general, the reliability of statistical model analyses is considered to be excellent for an AUC value of 0.9-1.0, good for a value of 0.8-0.89, moderate for a value of $0.7-0.79$, and low for a value of $0.51-0.69 .^{(20)}$ In this study, the years 2010 and 2014 showed excellent reliability; 2008, 2009, 2011, and 2018 showed good reliability; 2012 and 2019 showed moderate reliability, and 2016 showed low reliability.

Table 3

Landslide model reliability by year.

\begin{tabular}{ll}
\hline Year & AUC \\
\hline 2008 & 0.813 \\
2009 & 0.862 \\
2010 & 0.947 \\
2011 & 0.819 \\
2012 & 0.791 \\
2014 & 0.926 \\
2016 & 0.592 \\
2018 & 0.873 \\
2019 & 0.725 \\
\hline
\end{tabular}




\subsection{Landslide susceptibility maps and combined annual mapping}

Landslide locations varied over the nine-year study period, reflecting varying rainfall and wind speed patterns (Fig. 2). The mapping for 2008 showed that landslide-susceptible areas were distributed around the center of Gyeongnam, while in 2009, landslide-susceptible areas were concentrated in the east of the province. In 2010, landslides were concentrated in the northwest,

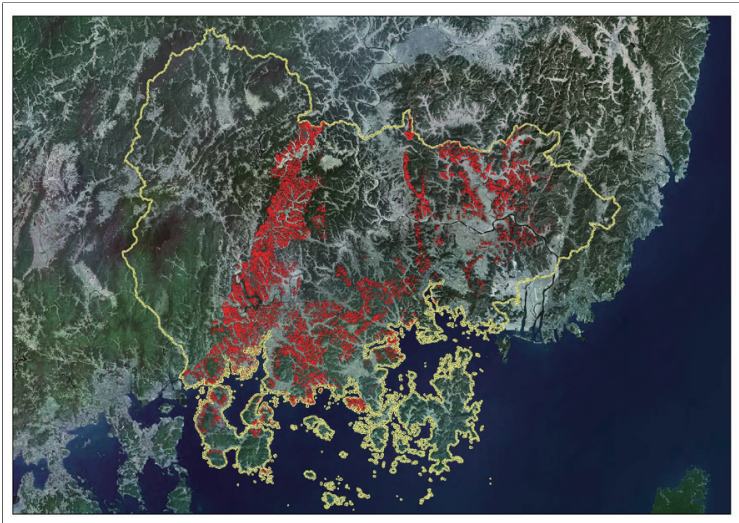

2008

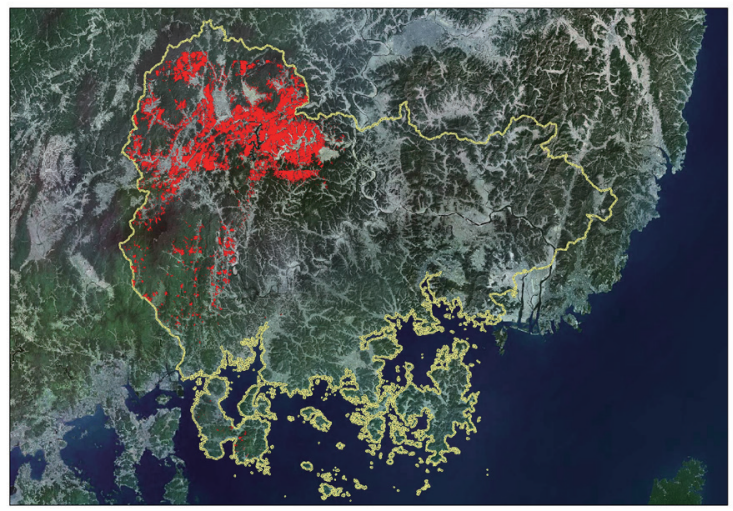

2010

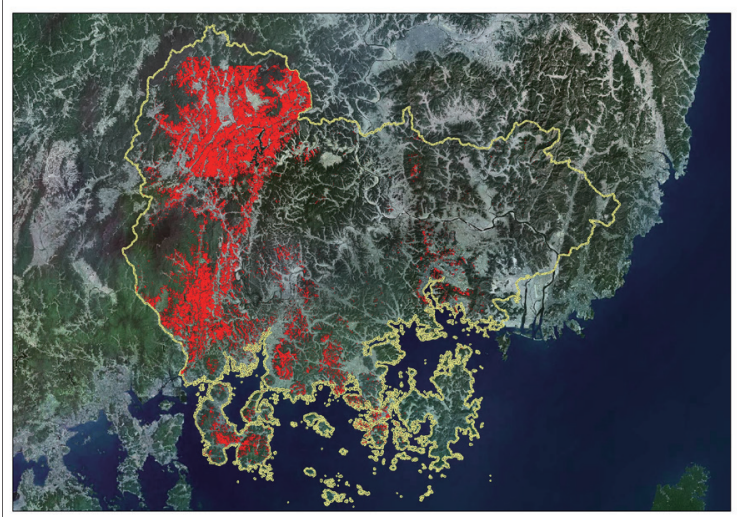

2012

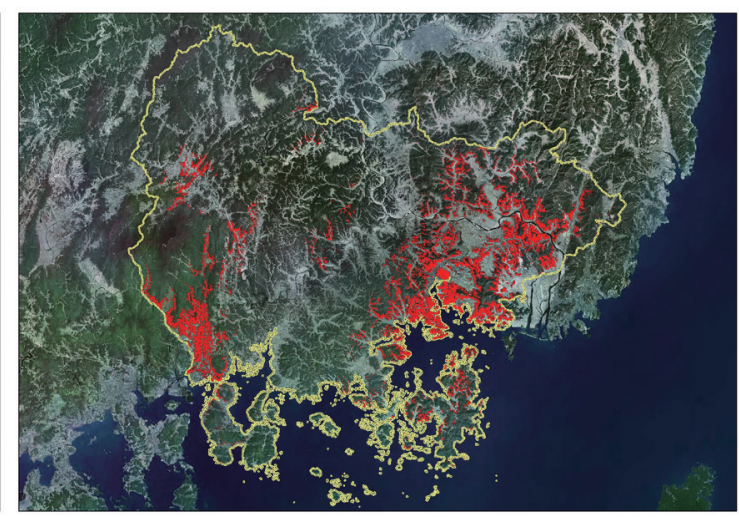

2009

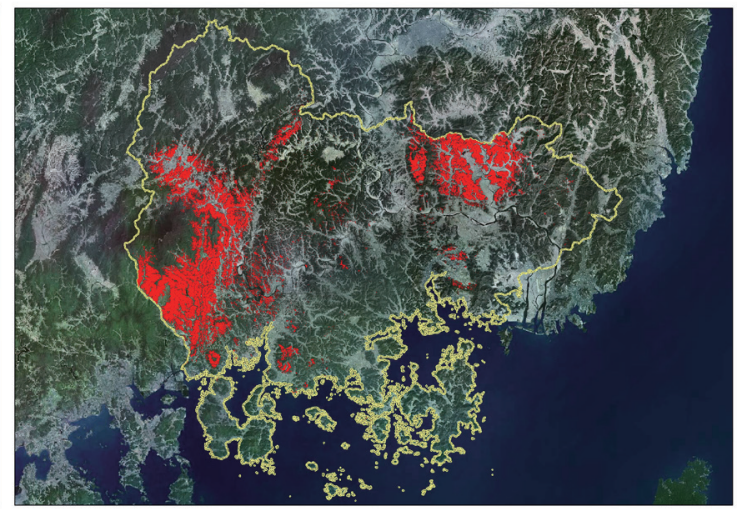

2011

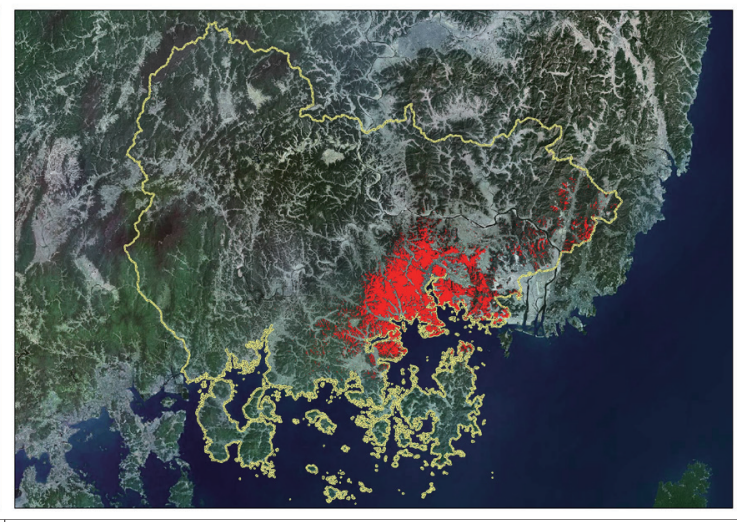

2014

Fig. 2. (Color online) Landslide-susceptible areas by year. 


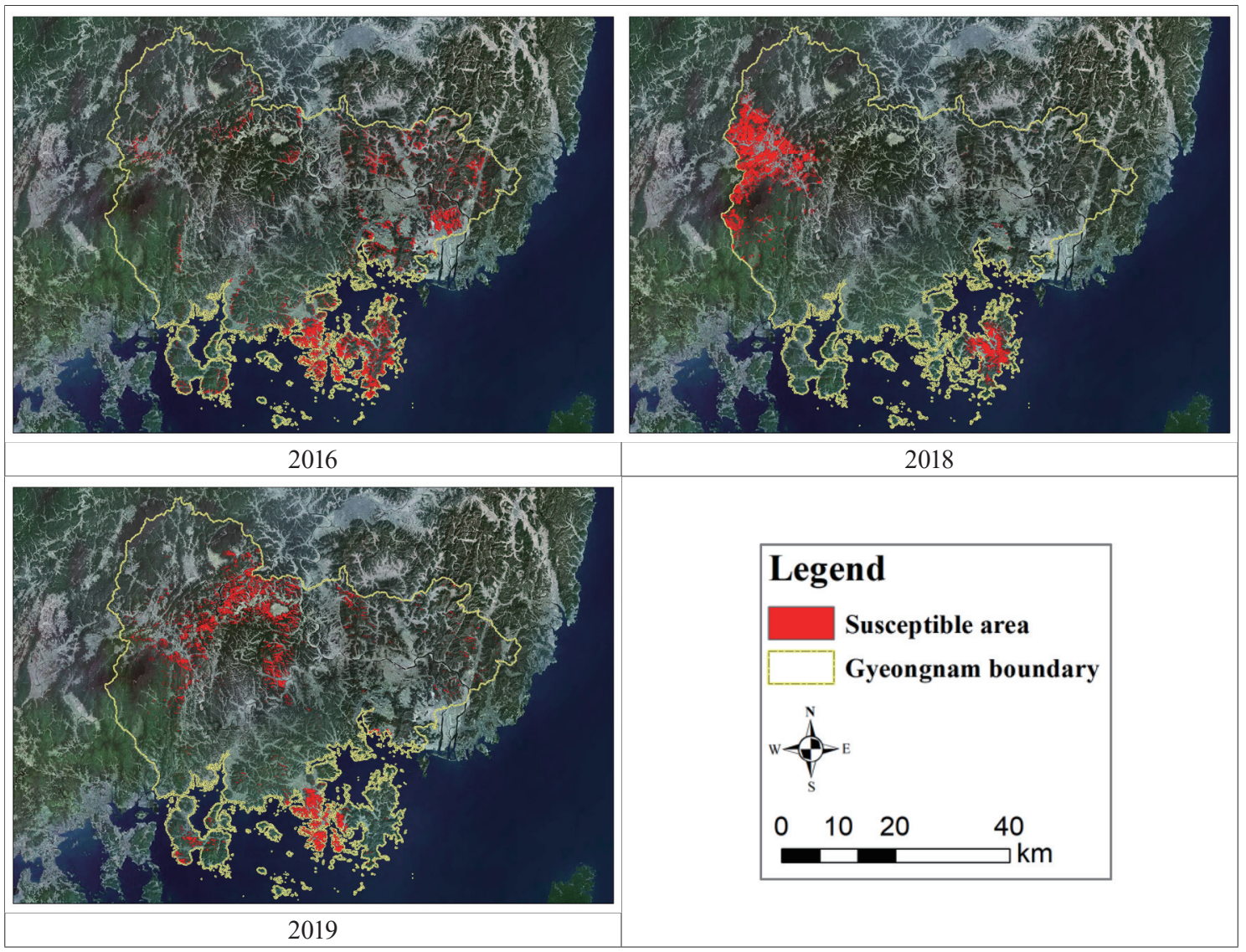

Fig. 2. (Continued) (Color online) Landslide-susceptible areas by year.

and in 2011, both the western and eastern regions included susceptible areas. Susceptible areas were concentrated in the west in 2012 and in the southeast in 2014. Landslide-susceptible areas were concentrated in the south in 2016, in the northwest in 2018, and in the northwest and south in 2019. These trends demonstrated the variation of landslide-susceptible areas over time, although the west, northwest, and southeast were most often evaluated as landslide-susceptible areas.

Considering the change in the annual landslide-susceptible area over time revealed that 2012 had the largest landscape-susceptible area, followed by 2011, 2009, and 2008 (Fig. 3). This trend was not necessarily related to the annual number of landslides and did not necessarily help identify areas with high probabilities of large or small landslides. It was also apparent that, although the landslide-susceptible area decreased significantly from 2012 to 2019, the area was still $\sim 500 \mathrm{~km}^{2}$ in 2014, 2016, 2018, and 2019.

To examine the cumulative landslide-susceptible area information over the nine years of interest, a combined landslide susceptibility map was created by overlapping the nine individual annual landslide susceptibility maps, where the results are presented in Fig. 4. The maximum number of times a single area was designated as a landslide-susceptible area was seven times, while areas nominated only once were left transparent to facilitate map interpretation. The areas 


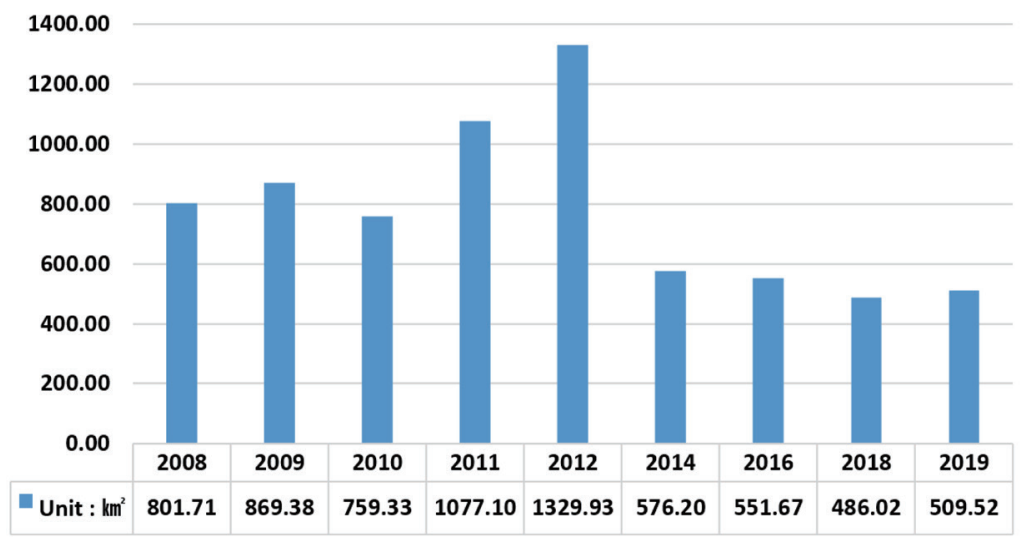

Fig. 3. (Color online) Changes in landslide-susceptible area over time.

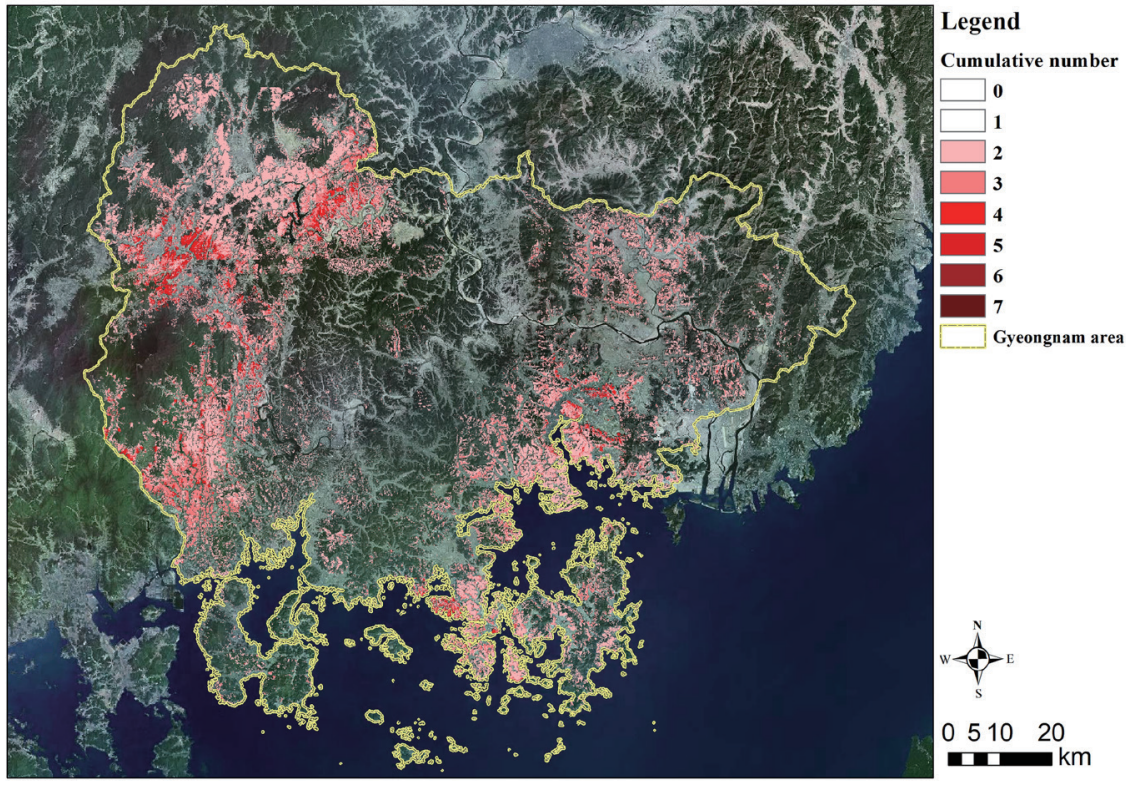

Fig. 4. (Color online) Comprehensive landslide susceptibility map covering 2008 to 2019.

corresponding to the cumulative number analyzed as landslide-susceptible areas were plotted as a graph, along with the ratio of the area relative to the total area of Gyeongnam in Fig. 5. The area designated as a susceptible area just once in nine years covered $\sim 2300 \mathrm{~km}^{2}$, accounting for $\sim 22 \%$ of Gyeongnam, while $\sim 580 \mathrm{~km}^{2}(\sim 5.52 \%)$ of the province was designated as a susceptible area between three and seven times.

\subsection{Landslide susceptibility in urban areas}

The landslide susceptibility in urban areas was analyzed by overlapping individual year landslide susceptibility maps onto the urbanization layer of the land cover map, and the calculated landslide susceptibility levels for each type of urbanized land use are listed in Table 4. 


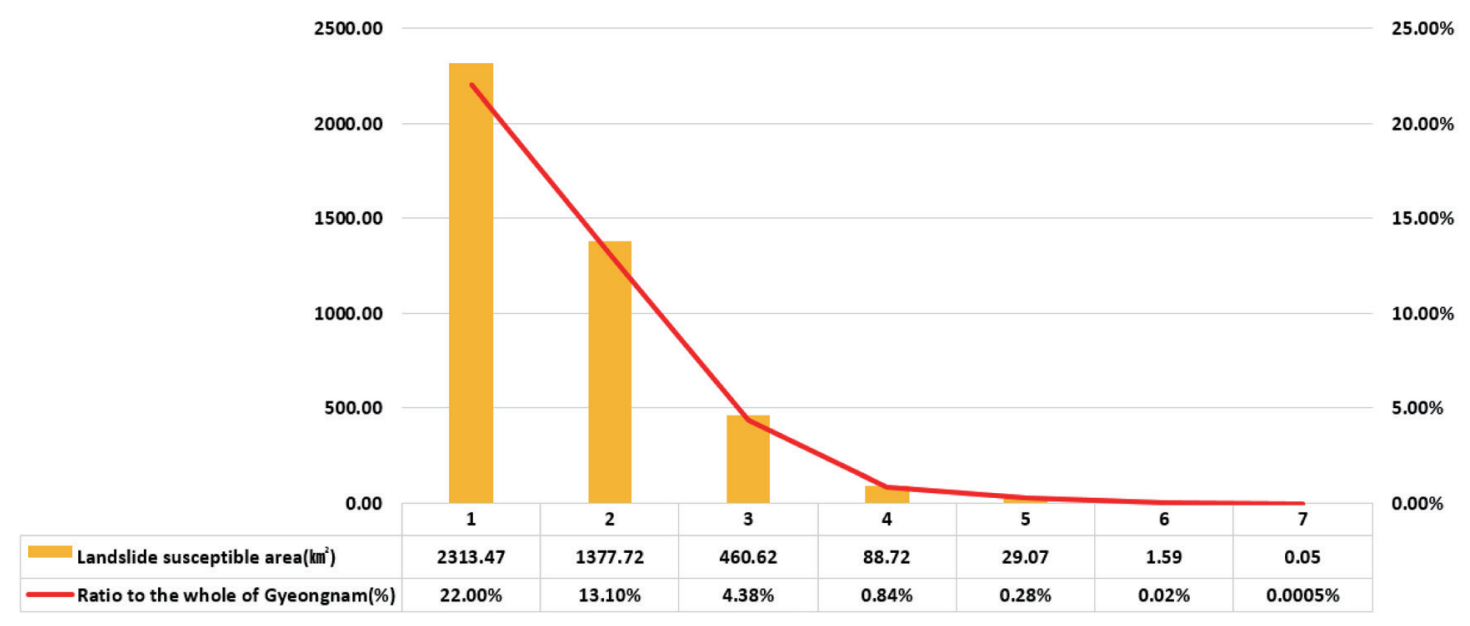

Fig. 5. (Color online) Area and percentage of Gyeongnam covered by landslide-susceptible areas with different cumulative numbers.

Table 4

Landslide area and ratio by urbanized area type.

\begin{tabular}{lccc}
\hline Urbanization area type & Total area by type $\left(\mathrm{km}^{2}\right)$ & Designated as susceptible area $\left(\mathrm{km}^{2}\right)$ & Ratio (\%) \\
\hline Residential & 103.2102 & 3.807 & 3.69 \\
Industrial & 36.9684 & 0.437 & 1.18 \\
Commercial & 47.7009 & 1.361 & 2.85 \\
Cultural & 5.3703 & 0.089 & 1.66 \\
Transportation & 364.5081 & 25.061 & 6.88 \\
Public facilities & 30.6666 & 1.636 & 5.34 \\
\hline
\end{tabular}

The results showed that land used for transportation had the largest landslide-susceptible area, followed by residential areas, public facilities, commercial areas, industrial areas, and cultural areas. The area of land used for transportation that was identified as susceptible to landslides exceeded the combined landslide-susceptible area for all other urbanized land uses.

To examine relative areas of land susceptible to landslides, as opposed to absolute areas, the ratio of the landslide-susceptible area to the total area of land was calculated for each land use. Land assigned to transportation showed the highest ratio, followed by land assigned to public facilities, residential areas, commercial areas, culture/sports/recreation areas, and finally industrial areas. Land assigned to transportation had the highest value for both criteria, confirming that such land is the most prone to landslides among urbanized areas with different uses.

\section{Discussion}

A novel feature of this study is that a landslide susceptibility assessment was conducted for multiple years. There is a limit to the precision with which the characteristics of landslide susceptibility of a target site can be clarified only by evaluating the susceptibility to landslides for a specific year. This is because the distribution of rainfall varies year by year. Therefore, by conducting research based on information on landslide locations and environmental variables 
over several years, it was possible to provide a more generalized evaluation of the landslide susceptibility of the target site than by giving the rainfall in a specific year.

Traffic areas (mainly road corridors), residential areas, and public facilities were found to be the urbanized areas with the highest landslide susceptibility. Traffic areas not only have the highest susceptibility but also have the largest landslide-susceptible area and the highest ratio of landslide-susceptible area, making transportation the urbanized land use type with the highest overall landslide susceptibility. This is considered to be related to the fact that major roads have often been constructed adjacent to steeply sloping forests for economic reasons. ${ }^{(20)}$

Our analysis showed that the reliability rating was lowest for the 2016 landslide-susceptible area calculation. This was attributed to the fact that the characteristics of the environmental variables at the 18 landslide sites of 2016 showed little commonality. When examining the response curve for each model variable, it was difficult to determine whether the maximum rainfall duration, maximum wind speed, slope, or soil drainage variables led to the high probability of landslide occurrence. Inconsistency in the environmental variable data reduced the reliability, and it will be necessary to review the 2016 landslide sites and environmental data records using archived remote sensing information to improve the reliability.

In this study, generalized annual data were used for variables other than rainfall and wind speed, rather than data corresponding to specific landslide times. Unlike continuous meteorological data, other environmental variables have limitations as their information is not provided in this format. This makes it important to understand that when applying the results from this study, such data limitations - principally the temporal inconsistency of environmental variables - can reduce model reliability. To respond to this, it is important that a research base of accumulated information covering at least one year for a variety of environmental variables is established, with data capture preferably matching the temporal range of this study.

\section{Conclusions}

In this study, the author analyzed data for Gyeongnam (ROK) landslide susceptibility, covering the nine active years of an 11-year study period, and produced a comprehensive landslide map. Through this, changes to the landslide-susceptible area distribution over time were revealed, and the numbers of times landslides occurred in specific locations were identified. Relationships between a compound landslide location map showing nine years of data and urbanization land use types were also analyzed, which resulted in transportation areas (mainly road traffic corridors), residential areas, and public facility areas being identified as having high landslide susceptibility, and their locations and characteristics were identified. In future studies, it will be necessary to apply various models to compensate for the uncertainty of the model. Also, this study emphasizes the need for periodic landslide sensing and monitoring, and illustrates the importance of collecting information on locations where landslides occur as material for landslide research. These results can be used as important reference data to reduce property damage and prevent loss of life from landslides. The methodology of this study can be used as a framework for analyzing the susceptibility of landslides and establishing countermeasures for urbanized areas located close to mountainous areas. 


\section{Acknowledgments}

This work was supported by the research grant of Research Institute of Industrial Sciences at Cheongju University (2020.03.01-2022.02.28).

\section{References}

1 H. G. Kim, D. K. Lee, C. Park, S. Kil, Y. Son, and J. H. Park: Environ. Earth Sci. 73 (2015) 3. https://doi. org/10.1007/s12665-014-3775-7

2 Yonhapnews: https://www.yna.co.kr/view/AKR20180930022400063 (accessed March 2021).

3 Korea Forest Service: https://m.korea.kr/news/pressReleaseView.do?newsId=156408892\#pressRelease (accessed March 2021).

4 D. T. Bui, T. A. Tuan, H. Klempe, B. Pradhan, and I. Revhaug: Landslides 13 (2016) 2. https://doi.org/10.1007/ s10346-015-0557-6

5 V. K. Pandey, H. R. Pourghasemi, and M. C. Sharma: Geocarto. Int. 35 (2020) 2. https://doi.org/10.1080/101060 49.2018.1510038

6 K. Nam, M. Lee, and G. Jeong: J. Eng. Geol. 26 (2016) 1. https://doi.org/10.9720/kseg.2016.1.23

7 E. Raso, D. Di Martire, A. Cevasco, D. Calcaterra, P. Scarpellini, and M. Firpo: J. Appl. Geol. (2020). https:// doi.org/10.1007/978-3-030-43953-8_18

8 D. V. Griffiths and R. M. Marquez: Geotechnique 57 (2007) 6. https://doi.org/10.1680/geot.2007.57.6.537

9 B. Yang, K. Yin, S. Lacasse, and Z. Liu: Landslides 16 (2019) 4. https://doi.org/10.1007/s10346-018-01127-x

10 A. M. S. Pradhan, H. Kang, J. Lee, and Y. Kim: Bull. Eng. Geol. Environ. 78 (2019) 1. https://doi.org/10.1007/ s10064-017-1055-y

11 L. Cascini, C. Bonnard, J. Corominas, R. Jibson, and J. Montero-Olarte: Landslide Hazard and Risk Zoning for Urban Planning and Development (Landslide Risk Manag Taylor Fr, London, 2005) pp. 199-235.

12 Korea Meteorological Administration: https://www.weather.go.kr/weather/climate/average_regional04.jsp (accessed March 2021).

13 Y. Hong, R. F. Adler, and G. Huffman: IEEE Trans. Geosci Remote Sens. 45 (2007) 6. https://doi.org/10.1109/ TGRS.2006.888436

14 J. D. Rogers, M. F. Ahmed, and E. H. Ismail: J. Environ. Eng. Geosci. 22 (2016) 4. https://doi.org/10.2113/ gseegeosci.22.4.297

15 D. Rozos, H. D. Skilodimou, C. Loupasakis, and G. D. Bathrellos: Environ. Earth Sci. 70 (2013) 7. https://doi. org/10.1007/s12665-013-2390-3

16 G. H. Kim, C. Y. Yune, H. G. Lee, and J. S. Hwang: J. Korean Soc. Surv. Geod. Photogramm. Cartogr. 29 (2011) 1. https://doi.org/10.7848/ksgpc.2011.29.1.47

17 K. M. Schmidt, J. J. Roering, J. D. Stock, W. E. Dietrich, D. R. Montgomery, and T. Schaub: Can. Geotech. J. 38 (2001) 5. https://doi.org/10.1139/cgj-38-5-995

18 Korea Meteorological Administration: https://ata.kma.go.kr/data/grnd/selectAsosRltmList.do?pgmNo=36 (accessed March 2021).

19 A. M. Felicísimo, A. Cuartero, J. Remondo, and E. Quirós: Landslides 10 (2013) 2. https://doi.org/10.1007/ s10346-012-0320-1

20 S. Rhim and W. Lee: J. Wildl. Manage. 71 (2007) 5. https://doi.org/10.2193/2005-584

\section{About the Author}

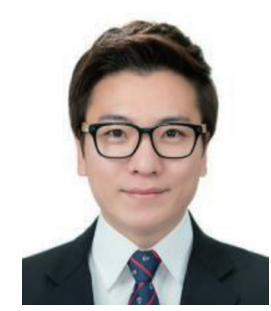

Ho Gul Kim received his B.Sc., M.Sc., and Ph.D. degrees from Seoul National University, Korea, in 2010, 2012, and 2017, respectively. Since 2018, he has been a professor at Cheongju University. His research interests include climate change, ecosystem services, and smart cities.(khgghk87@gmail.com) 